\title{
Cattle connection: molecular epidemiology of BVDV outbreaks via rapid nanopore whole-genome sequencing of clinical samples
}

Jacqueline King, Anne Pohlmann, Kamila Dziadek, Martin Beer and Kerstin Wernike*

\begin{abstract}
Background: As a global ruminant pathogen, bovine viral diarrhea virus (BVDV) is responsible for the disease Bovine Viral Diarrhea with a variety of clinical presentations and severe economic losses worldwide. Classified within the Pestivirus genus, the species Pestivirus A and B (syn. BVDV-1, BVDV-2) are genetically differentiated into 21 BVDV1 and four BVDV-2 subtypes. Commonly, the $5^{\prime}$ untranslated region and the $\mathrm{N}^{\text {pro }}$ protein are utilized for subtyping. However, the genetic variability of BVDV leads to limitations in former studies analyzing genome fragments in comparison to a full-genome evaluation.
\end{abstract}

Results: To enable rapid and accessible whole-genome sequencing of both BVDV-1 and BVDV-2 strains, nanopore sequencing of twelve representative BVDV samples was performed on amplicons derived through a tiling PCR procedure. Covering a multitude of subtypes (1b, 1d, 1f, 2a, 2c), sample matrices (plasma, EDTA blood and ear notch), viral loads (Cq-values 19-32) and species (cattle and sheep), ten of the twelve samples produced whole genomes, with two low titre samples presenting $96 \%$ genome coverage.

Conclusions: Further phylogenetic analysis of the novel sequences emphasizes the necessity of whole-genome sequencing to identify novel strains and supplement lacking sequence information in public repositories. The proposed amplicon-based sequencing protocol allows rapid, inexpensive and accessible obtainment of complete BVDV genomes.

Keywords: BVDV, Tiling PCR, Amplicon sequencing, Nanopore sequencing, Whole-genome sequencing, MinlON, BVDV-1, BVDV-2, Cattle

\section{Background}

Bovine viral diarrhea virus (BVDV), a worldwide pathogen of ruminants, belongs to the Pestivirus genus of the Flaviviridae family [1]. Currently, the four classical Pestivirus species, namely Pestivirus A (syn. BVDV-1), Pestivirus B (BVDV-2), Pestivirus $C$ (classical swine fever virus $(\mathrm{CSFV})$ ) and Pestivirus $D$

\footnotetext{
* Correspondence: kerstin.wernike@fli.de

Institute of Diagnostic Virology, Friedrich-Loeffler-Institut, Südufer 10, 17493 Greifswald - Insel Riems, Germany
}

(Border disease virus (BDV)), and some atypical pestiviruses are approved by the International Committee on Taxonomy of Viruses (ICTV) [2-4]. The atypical pestiviruses include the HoBi-like pestivirus (species Pestivirus $H$ ) detected in bovine calves and aborted fetuses [5-7], Bungowannah virus (Pestivirus $F$ ) identified in pigs in Australia [8], pronghorn antelope pestivirus (Pestivirus E) found in blind antelope in the United States [9], giraffe pestivirus (Pestivirus G) associated with mucosal-like disease in Kenyan

(c) The Author(s). 2021 Open Access This article is licensed under a Creative Commons Attribution 4.0 International License, which permits use, sharing, adaptation, distribution and reproduction in any medium or format, as long as you give appropriate credit to the original author(s) and the source, provide a link to the Creative Commons licence, and indicate if changes were made. The images or other third party material in this article are included in the article's Creative Commons licence, unless indicated otherwise in a credit line to the material. If material is not included in the article's Creative Commons licence and your intended use is not permitted by statutory regulation or exceeds the permitted use, you will need to obtain permission directly from the copyright holder. To view a copy of this licence, visit http://creativecommons.org/licenses/by/4.0/ The Creative Commons Public Domain Dedication waiver (http://creativecommons.org/publicdomain/zero/1.0/) applies to the data made available in this article, unless otherwise stated in a credit line to the data. 
giraffes [10], and novel pestiviruses in other species such as rats [11]. Further putative Pestivirus species have been described in various wildlife animals like bats and toothed whales $[12,13]$, yet await recognition as approved species. The ongoing detection in different host species and wide genomic range emphasizes the great genetic plasticity of the Pestivirus genus.

As one of the most important viral pathogens of ruminants across all continents, BVDV infections carry a significant economic and animal welfare impact [14], and have been reported in cattle, sheep, goats, pigs, deer, buffalo, bisons and alpacas [15-21]. While the course of disease ranges from subclinical to acute gastrointestinal, respiratory and reproductive signs, BVDV is also associated with immunosuppression or increasing morbidity rates in affected herds [22, 23]. In addition, intrauterine infection can potentially lead to vertical transmission, resulting in immunotolerant, persistently infected (PI) animals. Due to the lifelong shedding of high amounts of virus by PI animals they are the main source of infection for susceptible animals and uphold the infection cycle [24, 25], which makes them to the main target of disease control programs [26-28].

BVDV-1 and BVDV-2 can be distinguished according to genetic [29] and antigenic [30] characteristics. In Germany, around $95 \%$ of circulating BVDV strains belong to BVDV-1 [29, 31]. Comprising a single-stranded positive-sense RNA genome of approximately $12.3 \mathrm{~kb}$, a sole open reading frame (ORF) is flanked by 5' and 3' untranslated regions (5' UTR and 3' UTR). The genome encodes one large polyprotein subsequently processed by cellular and viral proteases into the twelve mature proteins $\mathrm{N}^{\text {pro }}$, C, E ${ }^{\text {rns }}, E 1, E 2, p 7$, NS2, NS3, NS4A, NS4B, NS5A, and NS5B [32]. Most phylogenetic analyses compare nucleotide sequences from the 5 ' UTR and $\mathrm{N}^{\text {pro }}$ regions of the viral genome [33, 34], currently resulting in the identification of 21 subtypes of BVDV-1 $(1 \mathrm{a}-1 \mathrm{u})$ and four subtypes of BVDV-2 $(2 \mathrm{a}-2 \mathrm{~d})$ [35-42]. In comparison, only two subtypes, BVDV-1a and BVDV-1b, were known in the early 1990s [43]. Additionally, point mutations due to the error-prone viral RNA-dependent RNA polymerase and (non)homologous RNA recombination are well known for pestiviruses, demonstrating the swift genetic evolution and heterogenicity of BVDV [44-48]. Thus, whole-genome sequencing is of great advantage for the precise and systematic genetic evaluation of BVDV. In line, previously conducted molecular epidemiology studies aiding national and international eradication programs are correspondingly built on the foundation of partial 5' UTR sequences [49-51].
Utilization of whole-genome sequences in combination with epidemiological data would likewise drastically improve molecular epidemiological investigations and offer additional insights of the attained full genome sequences for molecular-epidemiology.

Generation of whole-genome sequences from clinical samples is often challenging due to low virus loads or a limited sample integrity. Today, this can be successfully circumvented by tiling amplicon PCR schemes which have been successfully employed for a range of viruses, including Zika virus, Ebola virus and the recent severe acute respiratory syndrome coronavirus 2 (SARS-CoV-2) [52-55]. In comparison to other target enrichment methods, PCR offers cheap, fast, available and sensitive enrichment and amplification in one step. Amplicon sequencing using the third-generation Oxford Nanopore MinION device has proven to be a popular choice during outbreaks due to real-time, long read, cost effective sequencing with rapid turnaround [56, 57].

Here, we present a combined approach to aid in a rapid, cost effective and accessible generation of whole BVDV genomes from clinical materials, employing a primary tiling RT-PCR covering both BVDV-1 and BVDV2 species and real-time multiplex nanopore sequencing. Molecular epidemiology analysis of the results provides detailed insights of the circulating BVDV strains and allows the investigation of possible (direct and indirect) connections between outbreaks.

\section{Results}

\section{Sequencing data}

The universal applicability of the protocol was tested on twelve field BVDV samples representing multiple subtypes (BVDV 1b, 1d, 1f, 2a, 2c), with varying viral titres (Cq-values as measured by a panpesti real-time RT-PCR ranging from 19.2 to 32.6), two animal species (11 cattle and one sheep), and a variety of sample matrices (plasma, EDTA blood and ear notch tissue) (Table 1). Of the twelve sequenced samples, ten whole-genome sequences were attained. Sample 1 and sample 2 (both subtype 1b) achieved $96 \%$ fullgenome coverage (lack of coverage between nucleotide no. 1376 to 1856) with the proposed protocol while encompassing the highest Cq-values of 28.8 and 32.6, respectively (Additional File 3).

After pooling of the tiled amplicons and purification, all twelve samples had ample nucleic acid concentrations of $200-750 \mathrm{ng} / \mu \mathrm{l}$, easily meeting the requirements for sequencing. The Ligation Sequencing Kit produced 998, 034 demultiplexed, trimmed and quality checked reads in a 6-hour run, while the Rapid Barcoding Kit produced 7,762,073 demultiplexed, trimmed and quality checked reads in a 36-hour run. Exact read count and distribution is documented in Table 1. 
Table 1 Diagnostic samples included in the study

\begin{tabular}{|c|c|c|c|c|c|c|c|c|c|c|c|}
\hline & \multirow[t]{2}{*}{ Sample ID } & \multirow[t]{2}{*}{ Date } & \multirow[t]{2}{*}{ State } & \multirow[t]{2}{*}{ Species } & \multirow[t]{2}{*}{ ST } & \multirow[t]{2}{*}{ Matrix } & \multirow[t]{2}{*}{$\mathrm{Cq}$} & \multicolumn{2}{|c|}{ Read Count } & \multirow{2}{*}{$\begin{array}{l}\text { Total } \\
\text { Reads }\end{array}$} & \multirow{2}{*}{$\begin{array}{l}\text { Mapped } \\
\text { Reads }\end{array}$} \\
\hline & & & & & & & & Ligation & Rapid & & \\
\hline 1 & 2016BVD01435 & 2016 & $\mathrm{Nl}$ & Cattle & $1 b$ & Plasma & 28.8 & 38,635 & 442,964 & 481,599 & 48,145 \\
\hline 2 & 2016BVD01436 & 2016 & $\mathrm{Nl}$ & Sheep & $1 b$ & Plasma & 32.6 & 60,920 & 89,008 & 149,928 & 57,290 \\
\hline 3 & 2018BVD01695 & 2018 & $\mathrm{Nl}$ & Cattle & $1 f$ & Plasma & 19.2 & 66,753 & 850,149 & 916,902 & 824,299 \\
\hline 4 & 2018BVD06212 & 2018 & NW & Cattle & $1 d$ & EDTA blood & 22.6 & 89,898 & $1,255,060$ & $1,344,958$ & $1,277,809$ \\
\hline 5 & 2018BVD06214 & 2018 & NW & Cattle & $1 d$ & EDTA blood & 21.7 & 88,264 & 830,138 & 918,402 & 870,123 \\
\hline 6 & 2019BVD04871 & 2019 & NW & Cattle & $1 d$ & Plasma & 24.0 & 96,192 & 981,673 & $1,077,865$ & $1,040,017$ \\
\hline 7 & 2019BVD04882 & 2019 & NW & Cattle & $1 d$ & Plasma & 21.4 & 118,619 & $1,226,328$ & $1,344,947$ & $1,278,462$ \\
\hline 8 & 2019BVD04888 & 2019 & NW & Cattle & $1 d$ & EDTA blood & 19.4 & 83,659 & 707,704 & 791,363 & 427,131 \\
\hline 9 & 2019BVD04889 & 2019 & NW & Cattle & $1 d$ & EDTA blood & 28.0 & 157,898 & 314,612 & 472,510 & 229,627 \\
\hline 10 & 2017BVD04597 & 2017 & BW & Cattle & $1 b$ & Ear notch & 24.8 & 52,299 & 272,345 & 324,644 & 302,107 \\
\hline 11 & D66/11-28 & 2011 & $\mathrm{TH}$ & Cattle & $2 a$ & EDTA blood & 24.4 & 77,725 & 465,003 & 542,728 & 521,038 \\
\hline 12 & TV02/13, T136 & 2013 & - & Cattle & $2 c$ & Plasma & 21.5 & 67,172 & 327,089 & 394,261 & 385,679 \\
\hline
\end{tabular}

Legend: Selected samples with sample information, read counts divided between the Ligation Sequencing Kit and the Rapid Barcoding Kit, and mapped reads. ST Subtype, NI Lower Saxony, NW North Rhine-Westphalia, BW Baden-Württemberg, TH Thuringia

\section{Subtype $1 \mathrm{~b}$}

As one of the most common subtypes in Germany, three BVDV-1b samples were selected for protocol validation. This included two plasma samples from one holding in Lower Saxony (sample 1 and 2, 2016) but affecting different species (cattle and sheep) and both with high Cqvalues, and one bovine ear notch sample (sample 10) from Baden-Württemberg (2017) (Table 1).

In the case of sample 1 and sample 2, the question arose whether both animal species kept in the same holding were infected with an identical strain. Due to the high Cq-values of the samples, $96 \%$ whole-genome coverage was achieved (coverage range - sample 1: 08761 reads, sample 2: 0-9029 reads; Additional File 1 A) and revealed identity levels of $98.73 \%$ between both samples. Further genetic comparisons showed approximately $91 \%$ identity to the closest whole-genome database relatives: BVDV-1b strains identified in cattle in Brazil, 2014, and China, 2014 (Additional File 3).

In comparison to the previous BVDV-1b samples, sample 10 with a Cq-value of 24.8 was successfully sequenced from ear notch tissue to produce a whole genome with a mean coverage of 15,410-fold (coverage range - sample 10: $12-38,610$ reads; Additional File 1 A). Identity levels between the samples 1 and 2 and sample 10 were around $93 \%$, proving to show greater relatedness than other known available genomes (Fig. 1). Alike the previous BVDV-1b samples, approximately $93 \%$ identity to the described BVDV-1b strains from Brazil and China was recorded as the closest relatives (Additional File 3).

\section{Subtype 1d}

Six BVDV-1d samples collected in North RhineWestphalia from 2018/2019 were also fully sequenced
(Table 1). Although a frequently identified subtype in Europe, the lack of European BVDV-1d whole-genome sequences leaves strains identified in China (2012) and South Korea (2010) as the most similar available sequences with identity values of approximately $94 \%$. Mean coverage of the individual mappings ranged from 8455 -fold (sample 9) to 64,400-fold (sample 7) (coverage range - sample 4: 15-149,013 reads, sample 5: 10-98, 468 reads, sample 6: 11-109,466 reads, sample 7: 12152,077 reads, sample 8: 10-70,158 reads, sample 9: 1130,496 reads; Additional File 1 B). Albeit showing low virus loads, indicated by a Cq-value of 28.0, sample 9 was successfully sequenced to produce a whole-genome sequence (Additional File 3).

The six BVDV-1d samples originated from four cattle holdings in close proximity. Samples 4 and 5 originate from one holding (farm 1), as do samples 8 and 9 from a different holding (farm 4). Sample 6 and sample 7 were both collected at again different holdings (farm 2 and farm 3, respectively). Genomic evaluation of the wholegenome sequences allows the establishment of very high identity levels between the individual samples (>99.6\%) (Table 2). The highest nucleotide identity was observed between sample 4 and sample 5 (99.93\%), taken from the same holding in 2018. Likewise, sample 6 and sample 7 (2019) respectively shared the highest similarity with sample 5 , suggesting virus transmission between the farm 1 - farm 2 and farm 1 - farm 3 . The identity levels between sample 6 and sample 7 were slightly lower $(99.81 \%)$, potentially indicating no direct transmission between farm 2 and farm 3. In comparison, samples 8 and 9, originating from two calves born after one another in the same holding, show lower identity levels with the previously described BVDV-1d samples 


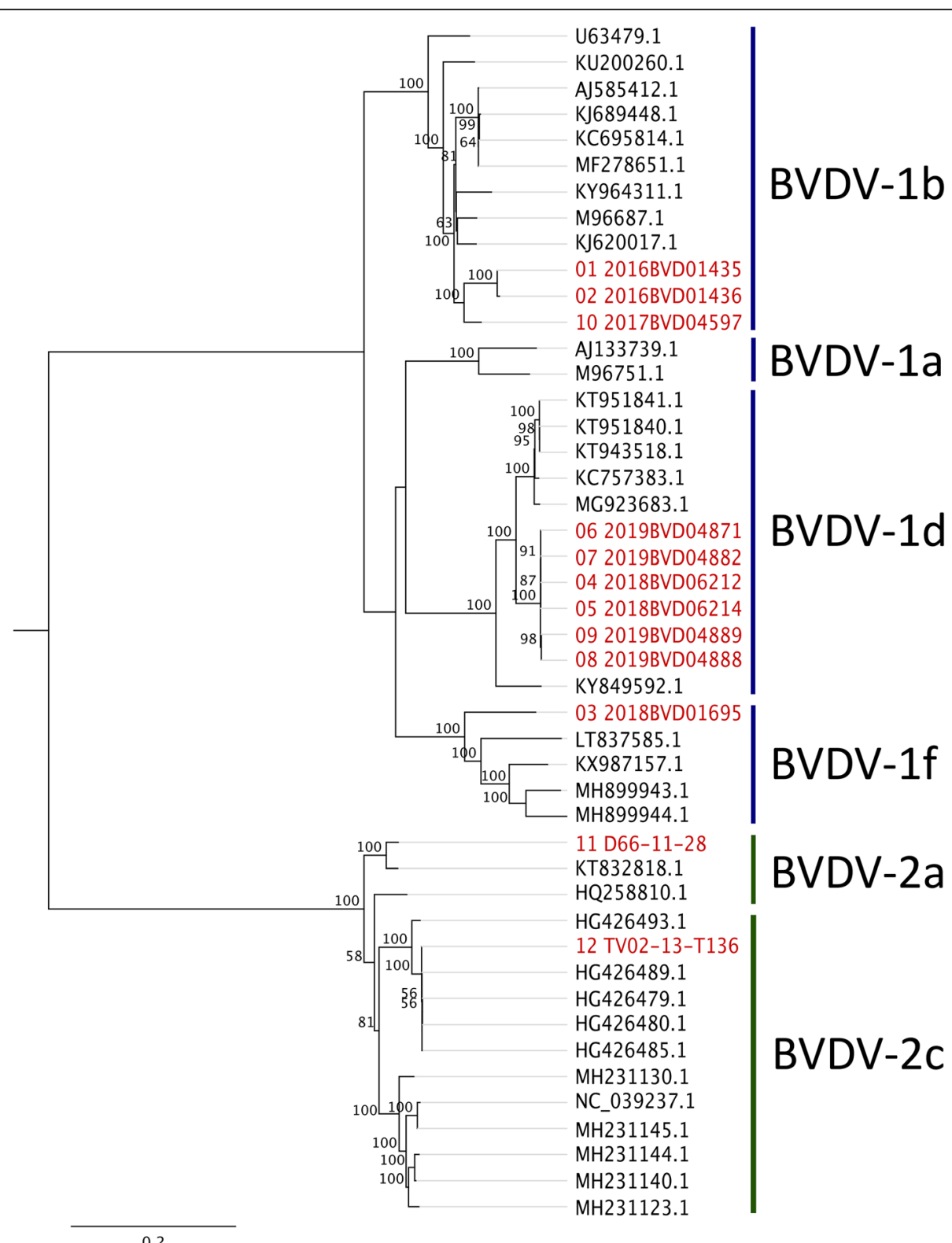

Fig. 1 Phylogenetic analysis. Analysis of all novel BVDV samples (highlighted in red) and representative whole-genome sequences from the GenBank database by Maximum Likelihood tree using RAxML with a bootstrap value of 1000 cycles.

(approximately $99.7 \%$ ), but again share a high sequence similarity of $99.89 \%$ (Fig. 1).

\section{Subtype 1f}

The sole BVDV-1f sample was successfully sequenced with a 48,083-fold coverage (sample 3) (coverage range sample 3: 25-132,836 reads; Additional File 1 A). The whole-genome sequence shares only approximately $85 \%$ identity with the nearest related strains from Slovenia (2000) and Italy (2012) (Additional File 3). Continuous circulation of the subtype $1 \mathrm{f}$ in the European bovine population is therefore likely. Although still grouping within BVDV-1f, this information confirms the broad genetic range within subtypes and the ongoing evolution over the past decade.

\section{Subtype $2 \mathrm{a}$ and $2 \mathrm{c}$}

Both BVDV-2 samples (BVDV-2a, sample 11 and BVDV-2c, sample 12) (Table 1) were successfully sequenced to produce whole genomes with a read coverage of 18,873-fold and 15,874-fold, respectively (coverage range - sample 11: 10-43,367 reads, sample 12: 2034,672 reads; Additional File $1 \mathrm{C}$ ). Identity levels of $90.36 \%$ were established between the described BVDV-2 
Table 2 Full genome identity levels of the consensus sequences of all BVDV-1d samples

\begin{tabular}{lllllll}
\hline Sample ID & 04 2018BVD06212 & 05 2018BVD06214 & 06 2019BVD04871 & 07 2019BVD04882 & 08 2019BVD04888 & 09 2019BVD04889 \\
\hline $042018 B V D 06212$ & NA & $99.93 \%$ & $99.83 \%$ & $99.88 \%$ & $99.74 \%$ & $99.75 \%$ \\
05 2018BVD06214 & $99.93 \%$ & NA & $99.86 \%$ & $99.92 \%$ & $99.76 \%$ & $99.79 \%$ \\
$062019 B V D 04871$ & $99.83 \%$ & $99.86 \%$ & NA & $99.81 \%$ & $99.69 \%$ & $99.72 \%$ \\
$072019 B V D 04882$ & $99.88 \%$ & $99.92 \%$ & $99.81 \%$ & NA & $99.71 \%$ & $99.74 \%$ \\
$082019 B V D 04888$ & $99.74 \%$ & $99.76 \%$ & $99.69 \%$ & $99.71 \%$ & NA & $99.89 \%$ \\
09 2019BVD04889 & $99.75 \%$ & $99.79 \%$ & $99.72 \%$ & $99.74 \%$ & $99.89 \%$ & NA \\
\hline
\end{tabular}

Identity is given in \%

samples. In comparison to public whole-genome sequences, sample 11 shared the highest identity rate of $96 \%$ with a BVDV-2a strain identified in the United States, 2013/2014 in a PI calf. Unsurprisingly, sample 12 carried high identity levels of $99.9 \%$ with previously sequenced BVDV-2c samples from Germany, 2013, as the sample 12 originated from an animal trial conducted with an isolate collected from the previously sequenced BVDV-2c outbreak in Germany, 2013 (Fig. 1, Additional File 3).

\section{Discussion}

The proposed tiling PCR in combination with real-time nanopore amplicon sequencing successfully produced ten whole genomes and two near-complete genomes of $96 \%$ coverage. Primer sets designed to encompass all known BVDV-1 and BVDV-2 subtypes enabled high viral read coverage, while lowering the necessary sequencing depth, and sequencing of samples with low viral titres. The MinION nanopore device allows a multiplex approach while being portable, accessible and costeffective, and additionally reduces overall preparation and sequencing time thanks to transposase-based library kits. Alongside successful testing of the presented method, sequencing of five subtypes additionally resulted in twelve new full genome sequences, often devising low identity levels to other available BVDV genomes.

While next-generation sequencers continue to be the gold standard for large data throughput at a moderate cost, clinical application is still limited due to complex protocols and large capital investment [58]. The introduction of cheap, portable and accessible thirdgeneration nanopore devices has started a new era of sequencers. Although the high error rate of MinION reads in comparison to other next-generation sequencers (Illumina, IonTorrent) still exists, ongoing improvements, for example, the R10 flow cells (ONT), and a multitude of bioinformatic analysis tools aid in reduction of the currently standing error profile. Many studies comparing the consequences of next- and third-generation sequencing on the final consensus quality have been conducted, showing that the error rates $(93-95 \%$ for ONT, > $99 \%$ for second-generation sequencers) only have a minor impact on the final sequence information and can be well compensated by higher read coverage [59-65]. As is typical for the utilization of a tiling PCR, the coverage of the samples varies depending of multiple factors, including the primer sequence, overlap of multiple primer pairs leading to higher coverage and the quality of the RNA template. The presented data achieved a minimum coverage of at least 10 reads in all areas (except two small dropouts in samples 1 and 2 - Additional File 1). This coverage is sufficient for the production of a reliable consensus sequence.

High-throughput sequencing has improved drastically over the past decade, radically reducing expenditures of time and money, yet in shot-gun approaches the host to virus read ratio still calls for great sequencing depth to achieve whole viral genomes [66]. Especially clinical or field samples often show high and disruptive background read levels. Thus, prior amplification by PCR can aid in reducing costs, sequencing depth and duration. In our study, the used primer pools are designed to cover all subtypes of either BVDV-1 or BVDV-2, additionally eliminating the need for prior subtyping and further reducing expenditures. However, it must be kept in mind that the upstream PCR may introduce biases. As most previous sequencing of $5^{\prime}$ UTR and $\mathrm{N}^{\text {pro }}$ segments was performed by PCR and Sanger sequencing without the possibility of in-depth analysis, the PCR bias was potentially higher or not identified in earlier studies. In addition, utilization of the upstream PCR could possibly lead to difficulties when identifying novel subtypes. As the primer pools are designed to map more conserved genome regions, acquirement of parts of the genome would still be possible. With the increase of public novel BVDV whole-genome sequences, the primer design could easily be adapted to match all new subtypes.

To date, a mere 378 whole-genome sequences of the entire coding region are available on the NCBI nucleotide database (date: 05.01.2021). In comparison to other RNA viruses, for example influenza A viruses or the new SARS-CoV-2 viruses where databases encode tens of thousands of full genomes [67], the public database comprises only limited BVDV sequence data. This complicates the genomic evaluation and comparison of full- 
genome sequences, leading to low identity levels between available strains. For example, BVDV-1f sample 3 shared only $85 \%$ sequence identity with the closest available whole-genome sequence although in phylogenetic analysis the sample still clustered within the BVDV-1f group (Fig. 1). Additionally, while the correct allocation only by analysis of short partial 5' UTR and $\mathrm{N}^{\text {pro }}$ sequences to the established pestivirus species is usually correct (BVDV-1 or BVDV-2), several publications have indicated limitations of inferring BVDV phylogenies using only partial genes. Especially the 5' UTR sequence lacks length and diversity, restricting the validity of correct allocations [68-70]. As shown by sample 1 and sample 2, the 5' UTR region of both sequences are $100 \%$ identical. If only this partial sequence information is considered, both the ovine and the bovine sample would be suspected to be epidemiologically linked. However, full-genome sequencing shows definitive nucleotide differences between the cases with a final nucleotide identity of $98.73 \%$, thus reducing the likelihood of direct transmission between both animals. Sequencing of BVDV samples would allow greater insights into the genetic diversity and enable the use of molecular epidemiology in outbreaks.

In comparison to samples 1 and 2 (two samples taken simultaneously in the same holding), all six BVDV-1d cases share extremely high similarity rates (>99.6\%) although sampling was executed over a two-year period (2018-2019) and including four different holdings. The close genetic relations could be attributed to a genetic stabilization of the circulating BVDV-1d strain in PI animals that are immunotolerant to this particular strain. Full-genome sequencing can allow in-depth molecular epidemiological analysis of the viruses in the affected holdings, thus enabling the identification of potential transmission events between individual cases. Here, the highest identity levels were observed between samples of one holding (samples 4 and 5). However, even though sample 6 and sample 7 were collected in the following year in two different holdings, both genomes were highly similar to especially sample 5 . This indicates direct transmission of the determined BVDV-1d strain from farm 1 to farm 2 and 3, potentially by mechanical, human or other vectors. As the nucleotide identity of sample 6 and sample 7 is lower, transmission between the individual holdings is less likely than transmission from farm 1 to farm 2 and farm 3 individually. Unsurprisingly, samples 8 and 9 share high identity levels. Although samples 8 and 9 show slightly lower nucleotide similarity to the other BVDV-1d cases, a transmission event from the originating holding is still likely. Due to the longer time period and thus evolution potential of the strain alongside near eradication of BVDV in Germany resulting in less potential infection sources, a close relation of all BVDV-1d samples is highly probable. Additional epidemiological outbreak investigation data could aid in the detection of certain transmission routes.

BVDV strains show a broad identity range within and between the individual subtypes. For example, BVDV-2a sample 11 and BVDV-2c sample 12 carried a nucleotide sequence divergence of approximately $10 \%$, while BVDV-1f sample 3 showed divergences of around 15\% within the respective subtype. Especially BVDV-1 subtypes have been reported with up to $16 \%$ divergence within the same group and up to $23 \%$ divergence between the subtypes $[29,71]$. Due to the lack of specific criteria for subtyping of new virus isolates, an underlying uncertainty exists in the BVDV classification system. A clear and encompassing approach with standardized taxonomy would greatly aid the analysis of genomic BVDV data [29].

\section{Conclusions}

With the help of the described and validated protocol, future rapid, accessible and cost-effective whole-genome sequencing of prior and circulating BVDV strains is facilitated. The ongoing growth and never-ending identification of novel subtypes calls for precise genetic evaluation, especially in areas utilizing BVDV vaccinations to ensure functionality of the vaccines. Phylogenetic and network analysis would likewise considerably profit from the production of novel BVDV whole genomes, allowing molecular epidemiological tracing of outbreaks and aiding in eradication programs.

\section{Methods}

\section{Sample selection and RNA extraction}

A panel of twelve BVDV samples were selected after subtyping based on the 5' UTR sequences as previously described [72] to include both BVDV species and common subtypes $1 \mathrm{~b}(n=3), 1 \mathrm{~d}(n=6), 1 \mathrm{f}(n=1), 2 \mathrm{a}(n=1)$ and 2c $(n=1)$. All BVDV-1 samples were collected as field samples in Germany between 2016 and 2019. The samples 1 (cattle) and 2 (sheep) originated from the same holding. BVDV-2 samples were collected in 2011 (subtype 2a, $n=1$, field sample) and 2013 (subtype 2c, $n=1$, sample collected during an experimental infection study at the Friedrich-Loeffler-Institut, Germany). Plasma, EDTA blood or ear notch material was the chosen sample matrix. With Cq-values ranging from 19.2 to 32.6, including multiple sample matrices and two host species (cattle and sheep), a respective subset mirroring field conditions was chosen for full-genome sequencing. Additional sample information can be found in Table 1. RNA of the respective strains was extracted from plasma and EDTA blood samples with the QIAamp Viral RNA Mini Kit (Qiagen, Hilden, Germany) and from the ear notch with the RNeasy Mini Kit 
(Qiagen, Hilden, Germany) according to the manufacturer's instructions.

\section{Tiling PCR and purification}

To facilitate full-genome sequencing, selected BVDV samples were amplified by tiling PCR. Primers were designed conferring to the sample genotypes and carefully selected to cover all subtypes of a respective BVDV species. To minimize the necessary number of PCR reactions while still guaranteeing functionality (for example avoiding overlapping primer pairs which would result in too small PCR fragments) the primers were pooled in equal parts $(20 \mathrm{pmol} / \mathrm{reaction}$ for each primer). This resulted in four primer pools for BVDV-1 samples and three primer pools for BVDV-2 samples. All primers were designed to cover approximately $900 \mathrm{bp}$ tiles with overlap to ensure full coverage (Fig. 2). Exact primer sequences and pooling instructions are recorded in Additional File 2.

The RT-PCR was performed using the SuperScript III One-Step RT-PCR kit (ThermoFisher Scientific, Darmstadt, Germany). For amplification, the reaction was carried out at the following temperature profile: reverse transcription at $50{ }^{\circ} \mathrm{C}$ for $30 \mathrm{~min}, \mathrm{PCR}$ initiation at $94{ }^{\circ} \mathrm{C}$ for $2 \mathrm{~min}$, and 40 cycles of a three-step cycling consisting of the denaturation at $94{ }^{\circ} \mathrm{C}$ for $15 \mathrm{~s}$, annealing at $56{ }^{\circ} \mathrm{C}$ for $30 \mathrm{~s}$, and extension at $68{ }^{\circ} \mathrm{C}$ for $90 \mathrm{~s}$. Ensuing pooling of the respective PCR products (BVDV-1-4 pools/sample, BVDV-2-3 pools/sample; Fig. 2), a subsequent purification step with the AMPure XP Magnetic Beads (Beckman Coulter, Fullerton, US) was performed in a 1:1 sample to beads ratio. Final quantification was achieved with the NanoDrop 1000 Spectrophotometer (ThemoFisher Scientific, Waltham, US).

\section{Whole-genome MinION sequencing}

The purified BVDV PCR products were sequenced on a MinION Mk1C platform (Oxford Nanopore Technologies
- ONT, Oxford, UK). Two multiplex sequencing methods were tested. This includes a transposase-based approach with the Rapid Barcoding Kit (SQK-RBK004, ONT) for rapid library preparation, and an end-ligation approach with the Ligation Sequencing Kit (SQK-LSK109, ONT) in combination with the Native Barcoding Expansion (EXPNBD104, ONT) for greater throughput.

While the Rapid Barcoding Kit utilizes a two-step transposase-directed method for simultaneous DNA cleaving and attachment of twelve distinct barcodes to the cleaved ends, followed by pooling of the multiplexed samples in the desired ratio and addition of sequencing adapters (approximately $20 \mathrm{~min}$ library preparation), the Ligation Sequencing Kit first repairs the DNA ends and uses dA-tailing for the ligation of dT-tailed unique barcodes, followed by pooling of the multiplexed samples and subsequent cohesion of sequencing adapters onto the "sticky" ends of the barcodes (approximately $3 \mathrm{~h} \mathrm{li}$ brary preparation). Both pooled and multiplexed libraries containing all 12 respective samples underwent realtime sequencing on a $\mathrm{Mk} 1 \mathrm{C}$ device with a standard R9.4.1 flow cell (FLO-MIN106D, ONT) in a 6-hour run (Ligation Sequencing Kit)/36-hour run (Rapid Barcoding Kit) utilizing fast basecalling with the basecaller Guppy (v3.2.9, ONT). The attained demultiplexed, quality checked and trimmed FastQ files were employed for further analysis.

\section{Data analysis and availability}

Analysis of the obtained sequencing data was conducted in Geneious Prime (v2021.0.3, Biomatters, New Zealand). After a further quality trimming step to remove all primer sequences and short reads $(<50$ bp reads), full-genome sequences were produced in an iterative map to reference approach with MiniMap2 [73] and the respective highest quality consensus sequence (threshold $60 \%$ identity) was selected for further phylogenetic analysis. Nucleotide alignment of the novel sequences and a representative subset of available BVDV

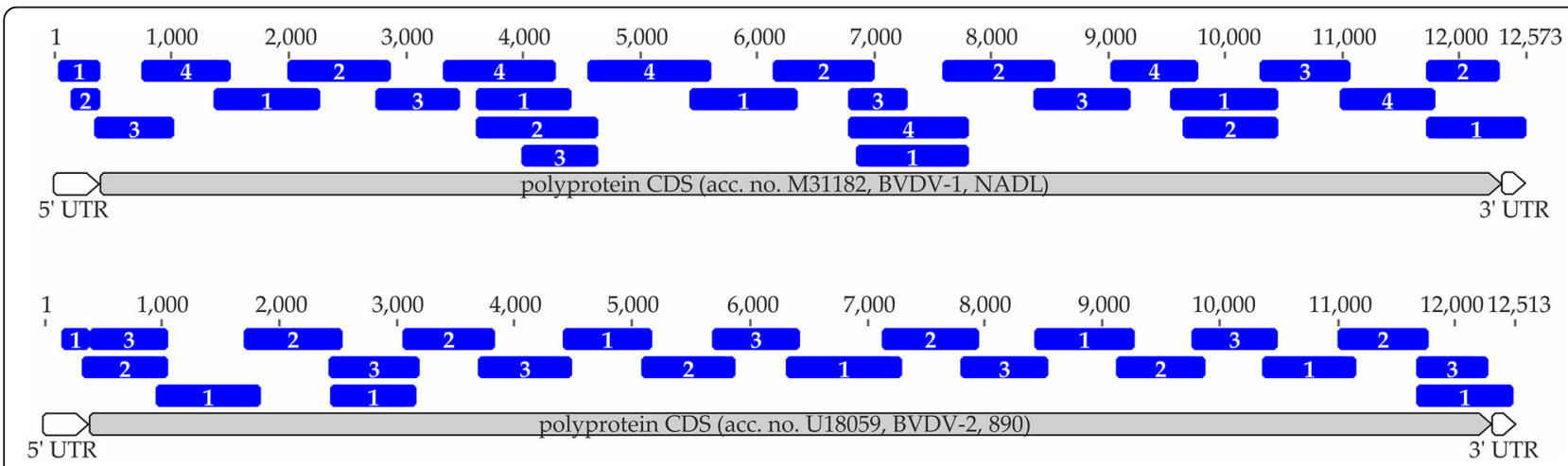

Fig. 2 Primer design, coverage and pooling guide for BVDV-1 and BVDV-2 strains. Pooling was performed in accordance with the numbers of the tiles (1-4), resulting in four primer pools for BVDV-1 (upper panel) and three primer pools for BVDV-2 (lower panel). 
full genome sequences in the INSDC database was conducted with MAFFT [74] as the foundation of the maximum likelihood analysis using RAxML [75] including 1000 bootstrap replicates. Additional sequence identity analyses were performed using NCBI BLAST (BLAST: Basic Local Alignment Search Tool) online.

All respective full-genome sequences obtained in this study were uploaded to the INSDC under the accession numbers MW528224 to MW528235 (Additional File 3).

\section{Abbreviations}

BLAST: Basic Local Alignment Search Tool; BDV: Border disease virus; BVDV: Bovine viral diarrhea virus; BW: Baden-Württemberg; CSFV: Classical swine fever virus; Cq: Quantification cycle; EDTA: Ethylenediaminetetraacetic acid; ICTV: International Committee on Taxonomy of Viruses; INSD

C: International Nucleotide Sequence Database Collaboration; NCBI: National Center for Biotechnology Information; NI: Lower Saxony; NW: North RhineWestphalia; ONT: Oxford Nanopore Technologies; ORF: Open reading frame; PI: Persistently infected; RAxML: Randomized Axelerated Maximum Likelihood; RNA: Ribonucleic acid; RT-PCR: Reverse transcription - Polymerase chain reaction; SARS-CoV-2: Severe acute respiratory syndrome coronavirus 2; ST: Subtype; TH: Thuringia; UTR: Untranslated region

\section{Supplementary Information}

The online version contains supplementary material available at https://doi. org/10.1186/s12917-021-02945-3.

Additional file 1. Mapping coverage presented in a logarithmic scale.

Additional file 2. Primer sequences and pooling guide.

Additional file 3. Additional sequencing data and GenBank accession number.

\section{Acknowledgements}

We would like to acknowledge Bianka Hillmann and Constantin Klein for their excellent technical assistance.

\section{Authors' contributions}

Conceptualization, K.W.; methodology, K.W. and A.P.; investigation, J.K., K.D. and K.W.; validation, J.K.; formal analysis, A.P. and J.K.; data curation, A.P. and J.K.; writing —original draft preparation, J.K.; writing—review and editing, K.W., A.P. and M.B.; visualization, J.K. and K.W.; supervision, A.P., K.W. and M.B.; funding acquisition, K.W., A.P. and M.B. All authors have read and agreed to the published version of the manuscript.

\section{Funding}

This research was supported by intramural funding of the Friedrich-LoefflerInstitut alongside partial funding from the European Union Horizon 2020 project "Versatile Emerging Infectious Disease Observatory", grant no. 874735, and the German Federal Ministry of Education and Research within project "PREPMEDVET", grant no. 13N15449. Open Access funding enabled and organized by Projekt DEAL.

\section{Availability of data and materials}

The data presented in this study are openly available in the INSDC repository under the accession numbers MW528224 to MW528235.

\section{Declarations}

\section{Ethics approval and consent to participate}

The diagnostic samples were taken by the responsible veterinarians in the context of the German mandatory BVD control program and as prescribed in the BVDV regulation (BVDV-Verordnung in der Fassung der Bekanntmachung vom 27. Juni 2016, BGBI. I S. 1483). No further permissions were necessary.

\section{Consent for publication}

Not applicable.

\section{Competing interests}

The authors declare no conflict of interest.

Received: 5 February 2021 Accepted: 18 June 2021

Published online: 12 July 2021

\section{References}

1. Houe H. Economic impact of BVDV infection in dairies. Biologicals. 2003; 31(2):137-43.

2. Smith DB, Meyers G, Bukh J, Gould EA, Monath T, Scott Muerhoff A, et al. Proposed revision to the taxonomy of the genus Pestivirus, family Flaviviridae. J Gen Virol. 2017;98(8):2106-12.

3. Simmonds P, Becher P, Bukh J, Gould EA, Meyers G, Monath T, et al. ICTV Virus Taxonomy Profile: Flaviviridae. J Gen Virol. 2017;98(1):2-3.

4. ICTV. Genus: Pestivirus 2019. Available from: https://talk.ictvonline.org/ictvreports/ictv_online_report/positive-sense-rna-viruses/w/flaviviridae/361/ genus-pestivirus.

5. Decaro N, Lucente MS, Mari V, Cirone F, Cordioli P, Camero M, et al. Atypical pestivirus and severe respiratory disease in calves, Europe. Emerg Infect Dis. 2011;17(8):1549-52.

6. Decaro N, Lucente MS, Mari V, Sciarretta R, Pinto P, Buonavoglia D, et al. Hobi-like pestivirus in aborted bovine fetuses. J Clin Microbiol. 2012;50(2): 509-12.

7. Peletto S, Zuccon F, Pitti M, Gobbi E, Marco LD, Caramelli M, et al. Detection and phylogenetic analysis of an atypical pestivirus, strain IZSPLV_To. Res Vet Sci. 2012:92(1):147-50.

8. Kirkland PD, Frost MJ, Finlaison DS, King KR, Ridpath JF, Gu X. Identification of a novel virus in pigs-Bungowannah virus: a possible new species of pestivirus. Virus Res. 2007;129(1):26-34.

9. Vilcek S, Ridpath JF, Van Campen $H$, Cavender $J$, Warg J. Characterization of a novel pestivirus originating from a pronghorn antelope. Virus Res. 2005; 108(1-2):187-93.

10. Becher P, Fischer N, Grundhoff A, Stalder H, Schweizer M, Postel A. Complete Genome Sequence of Bovine Pestivirus Strain PG-2, a Second Member of the Tentative Pestivirus Species Giraffe. Genome Announc. 2014;2(3).

11. Firth C, Bhat M, Firth MA, Williams SH, Frye MJ, Simmonds P, et al. Detection of zoonotic pathogens and characterization of novel viruses carried by commensal Rattus norvegicus in New York City. mBio. 2014;5(5):e01933-14.

12. Jo WK, van Elk C, van de Bildt M, van Run P, Petry M, Jesse ST, et al. An evolutionary divergent pestivirus lacking the N(pro) gene systemically infects a whale species. Emerg Microbes Infect. 2019;8(1):1383-92.

13. Wu Z, Ren X, Yang L, Hu Y, Yang J, He G, et al. Virome analysis for identification of novel mammalian viruses in bat species from Chinese provinces. J Virol. 2012;86(20):10999-1012.

14. Houe $\mathrm{H}$. Epidemiological features and economical importance of bovine virus diarrhoea virus (BVDV) infections. Vet Microbiol. 1999;64(2-3):89-107.

15. Goyal SM, Bouljihad M, Haugerud S, Ridpath JF. Isolation of bovine viral diarrhea virus from an alpaca. J Vet Diagn Invest. 2002;14(6):523-5.

16. Nelson DD, Duprau JL, Wolff PL, Evermann JF. Persistent Bovine Viral Diarrhea Virus Infection in Domestic and Wild Small Ruminants and Camelids Including the Mountain Goat (Oreamnos americanus). Front Microbiol. 2015;6:1415.

17. Ricci S, Bartolini S, Morandi F, Cuteri V, Preziuso S. Genotyping of Pestivirus A (Bovine Viral Diarrhea Virus 1) detected in faeces and in other specimens of domestic and wild ruminants at the wildlife-livestock interface. Vet Microbiol. 2019;235:180-7.

18. Passler T, Ditchkoff SS, Walz PH. Bovine Viral Diarrhea Virus (BVDV) in WhiteTailed Deer (Odocoileus virginianus). Front Microbiol. 2016;7:945.

19. Martucciello A, De Mia GM, Giammarioli M, De Donato I, lovane G, Galiero G. Detection of Bovine viral diarrhea virus from three water buffalo fetuses (Bubalus bubalis) in southern Italy. J Vet Diagn Invest. 2009;21(1):137-40.

20. Xu X, Zhang Q, Yu X, Liang L, Xiao C, Xiang H, et al. Sequencing and comparative analysis of a pig bovine viral diarrhea virus genome. Virus Res. 2006;122(1-2):164-70.

21. Hause BM, Pillatzki A, Clement T, Bragg T, Ridpath J, Chase CCL. Persistent infection of American bison (Bison bison) with bovine viral diarrhea virus and bosavirus. Vet Microbiol. 2021;252:108949.

22. Baker JC. The clinical manifestations of bovine viral diarrhea infection. Vet Clin North Am Food Anim Pract. 1995;11(3):425-45.

23. Larson RL. Bovine Viral Diarrhea Virus-Associated Disease in Feedlot Cattle Vet Clin North Am Food Anim Pract. 2015;31(3):367-80, vi. 
24. Garoussi MT, Mehrzad J, Nejati A. Investigation of persistent infection of bovine viral diarrhea virus (BVDV) in Holstein dairy cows. Trop Anim Health Prod. 2019;51(4):853-8.

25. Falkenberg SM, Dassanayake RP, Walz P, Casas E, Neill JD, Ridpath JF. Frequency of bovine viral diarrhea virus detected in subpopulations of peripheral blood mononuclear cells in persistently infected animals and health outcome. Vet Immunol Immunopathol. 2019;207:46-52.

26. Moennig V, Becher P. Control of Bovine Viral Diarrhea. Pathogens. 2018;7(1).

27. Moennig $\vee$, Becher P. Pestivirus control programs: how far have we come and where are we going? Anim Health Res Rev. 2015;16(1):83-7.

28. Wernike K, Gethmann J, Schirrmeier H, Schroder R, Conraths FJ, Beer M. Six Years (2011-2016) of Mandatory Nationwide Bovine Viral Diarrhea Control in Germany-A Success Story. Pathogens. 2017;6(4).

29. Yesilbag K, Alpay G, Becher P. Variability and Global Distribution of Subgenotypes of Bovine Viral Diarrhea Virus. Viruses. 2017;9(6).

30. Alpay G, Yesilbag K. Serological relationships among subgroups in bovine viral diarrhea virus genotype 1 (BVDV-1). Vet Microbiol. 2015;175(1):1-6.

31. Beer M, Wolf $G$, Kaaden OR. Phylogenetic analysis of the $5^{\prime}$-untranslated region of german BVDV type II isolates. J Vet Med B Infect Dis Vet Public Health. 2002;49(1):43-7.

32. Collett MS, Larson R, Belzer SK, Retzel E. Proteins encoded by bovine viral diarrhea virus: the genomic organization of a pestivirus. Virology. 1988;165(1):200-8.

33. Nagai M, Hayashi M, Sugita S, Sakoda Y, Mori M, Murakami T, et al. Phylogenetic analysis of bovine viral diarrhea viruses using five different genetic regions. Virus Res. 2004;99(2):103-13.

34. Silveira S, Weber MN, Mosena AC, da Silva MS, Streck AF, Pescador CA, et al. Genetic Diversity of Brazilian Bovine Pestiviruses Detected Between 1995 and 2014. Transbound Emerg Dis. 2017;64(2):613-23.

35. Giangaspero M, Harasawa R, Weber L, Belloli A. Taxonomic and epidemiological aspects of the bovine viral diarrhoea virus 2 species through the observation of the secondary structures in the $5^{\prime}$ genomic untranslated region. Vet Ital. 2008;44(2):319-45.

36. Deng M, Ji S, Fei W, Raza S, He C, Chen Y, et al. Prevalence study and genetic typing of bovine viral diarrhea virus (BVDV) in four bovine species in China. PLoS One. 2015;10(4):e0121718.

37. Giammarioli M, Ceglie L, Rossi E, Bazzucchi M, Casciari C, Petrini S, et al. Increased genetic diversity of BVDV-1: recent findings and implications thereof. Virus Genes. 2015;50(1):147-51.

38. Jackova A, Novackova M, Pelletier C, Audeval C, Gueneau E, Haffar A, et al. The extended genetic diversity of BVDV-1: typing of BVDV isolates from France. Vet Res Commun. 2008;32(1):7-11.

39. Nagai $M$, Hayashi $M$, Itou $M$, Fukutomi $T$, Akashi $H$, Kida $H$, et al. Identification of new genetic subtypes of bovine viral diarrhea virus genotype 1 isolated in Japan. Virus Genes. 2008;36(1):135-9.

40. Timurkan MO, Aydin H. Increased genetic diversity of BVDV strains circulating in Eastern Anatolia, Turkey: first detection of BVDV-3 in Turkey. Trop Anim Health Prod. 2019;51(7):1953-61.

41. Vilcek S, Paton DJ, Durkovic B, Strojny L, Ibata G, Moussa A, et al. Bovine viral diarrhoea virus genotype 1 can be separated into at least eleven genetic groups. Arch Virol. 2001;146(1):99-115

42. Xue F, Zhu YM, Li J, Zhu LC, Ren XG, Feng JK, et al. Genotyping of bovine viral diarrhea viruses from cattle in China between 2005 and 2008. Vet Microbiol. 2010;143(2-4):379-83.

43. Ridpath JF, Bolin SR. Differentiation of types $1 \mathrm{a}, 1 \mathrm{~b}$ and 2 bovine viral diarrhoea virus (BVDV) by PCR. Mol Cell Probes. 1998;12(2):101-6.

44. Domingo E, Martinez-Salas E, Sobrino F, de la Torre JC, Portela A, Ortin J, et al. The quasispecies (extremely heterogeneous) nature of viral RNA genome populations: biological relevance-a review. Gene. 1985;40(1):1-8.

45. Gallei A, Orlich M, Thiel HJ, Becher P. Noncytopathogenic pestivirus strains generated by nonhomologous RNA recombination: alterations in the NS4A/ NS4B coding region. J Virol. 2005:79(22):14261-70.

46. Becher $P$, Orlich M, König M, Thiel HJ. Nonhomologous RNA recombination in bovine viral diarrhea virus: molecular characterization of a variety of subgenomic RNAs isolated during an outbreak of fatal mucosal disease. J Virol. 1999;73(7):5646-53

47. Jones $L R$, Weber EL. Homologous recombination in bovine pestiviruses. Phylogenetic and statistic evidence. Infect Genet Evol. 2004;4(4):335-43.

48. Weber MN, Streck AF, Silveira S, Mosena ACS, da Silva MS, Canal CW Homologous recombination in pestiviruses: identification of three putative novel events between different subtypes/genogroups. Infect Genet Evol. 2015;30:219-24
49. Stalder H, Hug C, Zanoni R, Vogt HR, Peterhans E, Schweizer M, et al. A nationwide database linking information on the hosts with sequence data of their virus strains: A useful tool for the eradication of bovine viral diarrhea (BVD) in Switzerland. Virus Res. 2016;218:49-56.

50. Wang L, Wu X, Wang C, Song C, Bao J, Du J. Origin and transmission of bovine viral diarrhea virus type 1 in China revealed by phylodynamic analysis. Res Vet Sci. 2020;128:162-9.

51. Stahl K, Kampa J, Baule C, Isaksson M, Moreno-Lopez J, Belak S, et al. Molecular epidemiology of bovine viral diarrhoea during the final phase of the Swedish BVD-eradication programme. Prev Vet Med. 2005;72(1-2):103-8; discussion 215-9.

52. Quick J, Grubaugh ND, Pullan ST, Claro IM, Smith AD, Gangavarapu K, et al. Multiplex PCR method for MinION and Illumina sequencing of Zika and other virus genomes directly from clinical samples. Nat Protoc. 2017;12(6): $1261-76$.

53. Quick J, Loman NJ, Duraffour S, Simpson JT, Severi E, Cowley L, et al. Realtime, portable genome sequencing for Ebola surveillance. Nature. 2016; 530(7589):228-32.

54. Wang M, Fu A, Hu B, Tong Y, Liu R, Liu Z, et al. Nanopore Targeted Sequencing for the Accurate and Comprehensive Detection of SARS-CoV-2 and Other Respiratory Viruses. Small. 2020;16(32):e2002169.

55. Li J, Wang H, Mao L, Yu H, Yu X, Sun Z, et al. Rapid genomic characterization of SARS-CoV-2 viruses from clinical specimens using nanopore sequencing. Sci Rep. 2020;10(1):17492.

56. King J, Schulze C, Engelhardt A, Hlinak A, Lennermann SL, Rigbers K, et al. Novel HPAIV H5N8 Reassortant (Clade 2.3.4.4b) Detected in Germany. Viruses. 2020;12(3)

57. Hoenen T. Sequencing of Ebola Virus Genomes Using Nanopore Technology. Bio Protoc. 2016;6(21).

58. Levy SE, Myers RM. Advancements in Next-Generation Sequencing. Annu Rev Genomics Hum Genet. 2016;17:95-115.

59. van Dijk EL, Jaszczyszyn $Y$, Naquin D, Thermes $C$. The Third Revolution in Sequencing Technology. Trends Genet. 2018;34(9):666-81.

60. Lu H, Giordano F, Ning Z. Oxford Nanopore MinION Sequencing and Genome Assembly. Genomics Proteomics Bioinformatics. 2016;14(5): 265-79.

61. Leggett RM, Clark MD. A world of opportunities with nanopore sequencing J Exp Bot. 2017;68(20):5419-29.

62. Smith C, Halse TA, Shea J, Modestil H, Fowler RC, Musser KA, et al. Assessing Nanopore Sequencing for Clinical Diagnostics: a Comparison of NextGeneration Sequencing (NGS) Methods for Mycobacterium tuberculosis. J Clin Microbiol. 2020;59(1).

63. Kumar KR, Cowley MJ, Davis RL. Next-Generation Sequencing and Emerging Technologies. Semin Thromb Hemost. 2019;45(7):661-73.

64. Ambardar S, Gupta R, Trakroo D, Lal R, Vakhlu J. High Throughput Sequencing: An Overview of Sequencing Chemistry. Indian J Microbiol. 2016:56(4):394-404

65. King J, Harder T, Beer M, Pohlmann A. Rapid multiplex MinION nanopore sequencing workflow for Influenza A viruses. BMC Infect Dis. 2020;20(1):648.

66. Goodwin S, McPherson JD, McCombie WR. Coming of age: ten years of next-generation sequencing technologies. Nat Rev Genet. 2016;17(6): 333-51.

67. Benson DA, Cavanaugh M, Clark K, Karsch-Mizrachi I, Ostell J, Pruitt KD, et al. GenBank. Nucleic Acids Res. 2018;46(D1):D41-D7.

68. Becher P, Orlich M, Shannon AD, Horner G, König M, Thiel HJ. Phylogenetic analysis of pestiviruses from domestic and wild ruminants. J Gen Virol. 1997; 78 (Pt 6):1357-66.

69. Chernick A, Godson DL, van der Meer F. Metadata beyond the sequence enables the phylodynamic inference of bovine viral diarrhea virus type 1a isolates from Western Canada. Infect Genet Evol. 2014;28:367-74.

70. Xia H, Liu L, Wahlberg N, Baule C, Belak S. Molecular phylogenetic analysis of bovine viral diarrhoea virus: a Bayesian approach. Virus Res. 2007;130(12):53-62.

71. Workman AM, Heaton MP, Harhay GP, Smith TP, Grotelueschen DM, Sjeklocha D, et al. Resolving Bovine viral diarrhea virus subtypes from persistently infected U.S. beef calves with complete genome sequence. J Vet Diagn Invest. 2016;28(5):519-28.

72. Wernike K, Schirrmeier H, Strebelow HG, Beer M. Eradication of bovine viral diarrhea virus in Germany-Diversity of subtypes and detection of livevaccine viruses. Vet Microbiol. 2017;208:25-9. 
73. Li H. Minimap2: pairwise alignment for nucleotide sequences. Bioinformatics. 2018;34(18):3094-100.

74. Katoh K, Standley DM. MAFFT multiple sequence alignment software version 7: improvements in performance and usability. Mol Biol Evol. 2013; 30(4):772-80.

75. Stamatakis A. RAxML version 8: a tool for phylogenetic analysis and postanalysis of large phylogenies. Bioinformatics. 2014;30(9):1312-3.

\section{Publisher's Note}

Springer Nature remains neutral with regard to jurisdictional claims in published maps and institutional affiliations.

Ready to submit your research? Choose BMC and benefit from:

- fast, convenient online submission

- thorough peer review by experienced researchers in your field

- rapid publication on acceptance

- support for research data, including large and complex data types

- gold Open Access which fosters wider collaboration and increased citations

- maximum visibility for your research: over $100 \mathrm{M}$ website views per year

At $\mathrm{BMC}$, research is always in progress. 